\title{
Tomada da palavra e conquista do tempo livre: uma entrevista com Jacques Rancière'
}

\author{
Jonas Tabacof Waks ${ }^{2}$ \\ ORCID: 0000-0002-3915-052X \\ José Sérgio Fonseca de Carvalho ${ }^{3}$ \\ ORCID: 0000-0002-0074-0872 \\ Lílian do Valle ${ }^{4}$ \\ ORCID: 0000-0002-8694-9297 \\ María Beatriz Greco ${ }^{5}$ \\ ORCID: 0000-0003-0308-3246
}

\section{Resumo}

Esta entrevista, concedida em fevereiro de 2021, explora os vínculos do pensamento de Jacques Rancière com a filosofia da educação. Inicialmente, o filósofo aborda aspectos de sua trajetória intelectual, sua relação com maio de 68 e suas pesquisas nos arquivos operários, que nutriram a elaboração de obras como A noite dos proletários e o levaram a romper com os pressupostos de Louis Althusser sobre as relações entre saber e política. Em seguida, Rancière analisa a recepção de $O$ mestre ignorante, marcada, segundo ele, por leituras equivocadas que a identificam ora como uma obra sobre a história do pensamento pedagógico, ora como uma metodologia de ensino a ser aplicada. Ambas leituras ignoram a concepção de emancipação intelectual proposta por Joseph Jacotot e a visão do próprio Rancière acerca das relações entre teoria e prática. Na discussão sobre o artigo Escola, produção, igualdade, único de seus textos voltado prioritariamente ao que ele denomina forma-escola, o filósofo destaca a importância das diferentes noções de temporalidade com as quais trabalha e coloca em questão a capacidade que a escola teria, hoje, para promover igualdade e tempo livre (skholé), por ter se tornado a instituição finalizada por excelência, aproximando-se cada vez mais das lógicas da hierarquização e da desigualdade. Ao final, o diálogo envereda por uma reflexão sobre o presente: a ascensão da extrema-direita em países como o Brasil e os Estados Unidos da América, marcada por aquilo que Rancière denomina paixão pela desigualdade.

\section{Palavras-chave}

Jacques Rancière - Filosofia da educação - Tomada da palavra - Tempo livre - Igualdade.

1- Traduzida do francês por Jonas Tabacof Waks, com apoio da equipe do Grupo de Estudos e Pesquisas sobre Educação e Pensamento Contemporâneo (GEEPC/FEUSP). A versão em português foi revista e aprovada pelo próprio Jacques Rancière.

2- Universidade de São Paulo; Université Paris 8. São Paulo, SP, Brasil. Contato: jonaswaks@usp.br

3- Universidade de São Paulo, São Paulo, SP, Brasil. Contato: jsfcusp@usp.br

4- Universidade do Estado do Rio de Janeiro, Rio de Janeiro, RJ, Brasil. Contato: lilidovalle@gmail.com

5- Universidad de Buenos Aires, Buenos Aires, Argentina. Contato: beagreco@gmail.com 


\section{Enacting speech and conquering free time: an interview with Jacques Rancière}

\section{Abstract}

This interview, given in February 2021, explores the links between Jacques Rancière's thought and the philosophy of education. Initially, Rancière addresses some aspects of his intellectual trajectory, his relationship with the events of May 68 and his research in workers' archives, which nurtured the fabric of books such as The nights of labor and led him to break with Louis Althusser's assumptions on the relations between knowledge and politics. Then, Ranciere analyzes the reception of The ignorant schoolmaster, which is, according to him, marked by mistaken readings that associate it either to a book about the history of pedagogical thought or to a methodology to be applied. Both readings ignore Joseph Jacotot's conception of intellectual emancipation and Rancière's view of the relations between theory and practice. In the discussion on the article School, production, equality, his only text mainly dedicated to what he calls school-form, the philosopher highlights the importance of the different notions of temporality in his thought and questions the school's ability to promote equality and free time (skholé) today, as it has become the finalized institution by excellence, increasingly closer to the logics of hierarchy and inequality. In the end, the dialogue addresses a theme related to the present: the rise of the extreme right in countries like Brazil and the United States of America, marked by what Rancière calls passion for inequality.

\section{Keywords}

Jacques Rancière - Philosophy of education - Capture of speech - Free time - Equality.

\section{Apresentação}

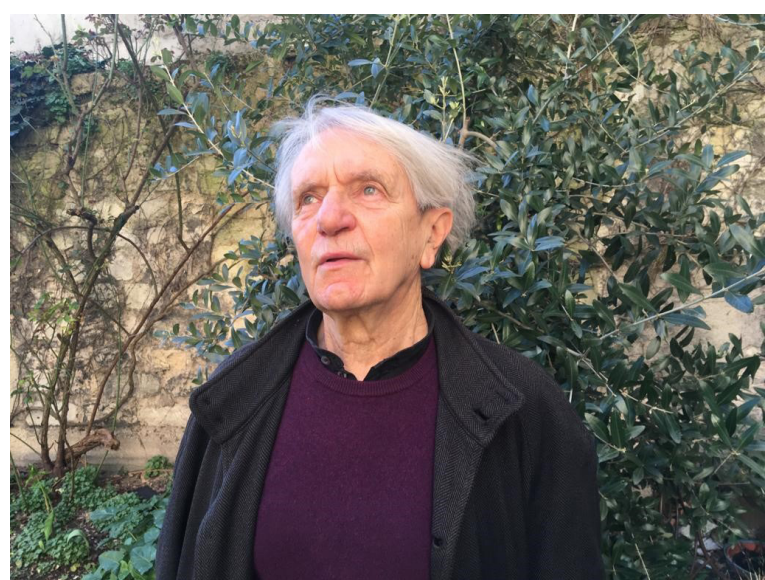

Fonte: Jacques Rancière em Paris, em 2021.

Crédito da foto: Philolike (CC by-sa 4.0).
O filósofo francês Jacques Rancière é considerado um dos mais importantes pensadores contemporâneos. Sua vasta produção tem repercutido em diversos campos do saber, como a filosofia e a teoria política, as artes e a educação. Em meio a essa diversidade de campos de interesse, o tema da igualdade desponta como elemento nuclear de suas reflexões. Caracterizada por um estilo de pensamento que embaralha as barreiras disciplinares e mescla diferentes vozes sem hierarquizá-las, sua obra rompe com o vezo acadêmico de tomar as falas 
silenciadas como material bruto cuja significação deveria ser construída pelo intelectual. Essas características tornam sua filosofia um pensamento instigante e fecundo para a compreensão do presente.

Nascido em 1940, na Argélia, Rancière migrou muito cedo com a família para Marselha, onde viveu por três anos. Em 1945, mudou-se para Paris, onde vive até hoje, como professor emérito de estética e política da Universidade Paris 8. Foi por meio dos livros de Jean-Paul Sartre que teve seu primeiro contato com a filosofia, mas ao ingressar na prestigiosa Escola Normal Superior (ENS) de Paris, interessou-se pela obra de Karl Marx e passou a frequentar os seminários de Louis Althusser dedicados à leitura estruturalista da obra do pensador alemão. A primeira publicação de Rancière foi um capítulo na obra coletiva Ler $O$ capital ([1965] 1979), escrita por Althusser e um seleto grupo de alunos da ENS. Nesse período, o jovem filósofo também era membro do grupo de estudantes comunistas da Escola Normal e, no contexto posterior às revoltas de maio de 1968, tornou-se maoísta. Entre 1969 e 1972, militou na Esquerda proletária, organização de extrema-esquerda que fazia trabalho de base em portas de fábricas e bairros populares.

As insurreições de maio de 1968 marcaram profundamente o pensamento e a trajetória de Rancière. Foi a partir desse momento que surgiram suas divergências com Althusser, notadamente no que concerne à sua visão acerca dos intelectuais na condução do movimento social e estudantil. Tais divergências o levaram a romper com seu antigo mestre, iniciando um trabalho autoral e inovador. Em 1969, começou a lecionar filosofia (ao lado de Michel Foucault e Gilles Deleuze, entre outros) no Centro Experimental de Vincennes, que depois se tornaria a Universidade Paris 8, onde trabalhou até se aposentar, no ano 2000. Seu primeiro curso nessa instituição versava sobre $A$ ideologia alemã de Marx, mas o seminário acabou por se converter numa crítica da teoria da ideologia de Althusser. A polêmica tornou-se pública em 1974, com a publicação do livro La leçon d'Althusser ([1974] 2011), no qual Rancière critica o dogmatismo de seu ex-professor e o papel que ele atribuía à ciência marxista - supostamente um privilégio distintivo dos dirigentes e intelectuais do Partido Comunista - nos processos de emancipação, o que para Rancière reafırmava relações de dependência.

Em 1975, junto a outros jovens filósofos, Rancière fundou o Centro de pesquisas sobre as ideologias da revolta, responsável pela publicação da revista Les Révoltes logiques. Inspirados em Foucault, mergulharam em arquivos e publicaram 16 números da revista, entre 1975 e 1981. A pesquisa de Rancière se dedicava à palavra operária e aos processos de autoemancipação dos proletários, com foco no período de 1830 a 1850 , justamente o momento em que o jovem Marx escrevia seus primeiros trabalhos, na aurora dos movimentos operário e comunista. No contato com os arquivos, Rancière descobriu a importância das dimensões estética e intelectual do movimento de emancipação operária, negligenciada pela maior parte dos teóricos marxistas. Sua tese de doutorado, A noite dos proletários: arquivos do sonho operário ([1981] 1988), está profundamente ligada aos temas e ao estilo de trabalho da revista e indica a centralidade da noção de tempo livre na concepção de emancipação proletária, entendida por Rancière como ruptura no ciclo repetitivo do trabalho e do repouso. Essa publicação marca também uma mudança no trabalho de escrita de Rancière, que abandona a concepção do intelectual como aquele 
que organiza, articula e desvenda o significado dos discursos, imagens e metáforas que recolhe entre aqueles cujas falas são confiscadas na partilha social. A partir de então, muitas de suas obras se configuram como narrativas polifônicas, nas quais embaralha sua fala e a dos proletários poetas, escritores e filósofos que estuda.

A década de 1980 foi marcada, na França, pela chegada dos socialistas ao poder e pela ampla circulação das ideias de Pierre Bourdieu. 0 sociólogo passou então a ser um dos principais alvos das críticas de Rancière, que analisa sua obra no livro Le Philosophe et ses pauvres ([1983] 2007), onde Bourdieu é associado a uma tradição que remonta a Platão - e passa pelo marxismo ortodoxo -, marcada pela exclusão dos trabalhadores da vida intelectual. É justamente a afirmação da igualdade intelectual que estará no cerne de O mestre ignorante: cinco lições sobre a emancipação intelectual ([1987] 2015), obra na qual Rancière resgata a voz dissonante de Joseph Jacotot e sua concepção de emancipação intelectual fundada no postulado da igualdade das inteligências. Com Jacotot, Rancière opunha-se tanto a Althusser - na medida em que recusava o papel da ciência marxista e da vanguarda esclarecida nos processos de emancipação - quanto à apropriação que os discursos pedagógicos fizeram da obra Bourdieu, ao propor uma escola adaptada à realidade das crianças das camadas desfavorecidas. Para Rancière, ambas visões reafirmavam a desigualdade ao postular a igualdade como meta futura, a ser conquistada em etapas, mas que sempre permanece como um horizonte para o futuro.

A partir dos anos 1990, Rancière publicou uma série de trabalhos em que sistematiza suas concepções de política e democracia, como $O$ desentendimento ([1995] 1996) e $O$ ódio $\dot{a}$ democracia ([2005] 2014). 0 filósofo define a política como as ações que fazem com que as vozes normalmente ouvidas apenas como um ruído - que atrapalha, mas não faz parte do debate - sejam de fato escutadas como discurso; como a fala de um igual. Embora fugazes, esses momentos marcam a tomada da palavra como um ato de afirmação da igualdade. Seu oposto é a polícia, por ele entendida como a distribuição ordenada e a manutenção de cada grupo social em seu lugar próprio. A democracia nada tem a ver, pois, com o consenso - acerca da distribuição de falas e posições legítimas - mas, ao contrário, brota da potencialidade do dissenso, que rompe com a cristalização de lugares próprios.

Desde os anos 2000, Rancière tem se dedicado principalmente à estética, analisada sempre em sua imbricação com a política, como nas obras $A$ partilha do sensível ([2000] 2005) e $O$ espectador emancipado ([2008] 2012). A origem das reflexões estéticas de Rancière pode ser remetida a seus primeiros trabalhos, pois foi nos estudos sobre a emancipação operária que ele descobriu a centralidade da estética, especialmente da escrita. Contudo, a partir das reflexões sobre as políticas da escrita, o filósofo se envereda pela própria teoria estética, com a discussão sobre os regimes da arte.

Entre educadores e educadoras, $O$ mestre ignorante é certamente sua obra mais conhecida. 0 resgate que Rancière faz da aventura intelectual de Jacotot é profundamente original em seu estilo, lançando mão de uma narrativa que mescla as experiências e reflexões de um professor da primeira metade do século XIX com as de um filósofo do final do século XX. 0 diálogo entre esse legado do passado e sua reapropriação no presente desafia as bases sobre as quais se erigiram os discursos pedagógicos, como a função explicadora do mestre e a estipulação de etapas e meios apropriados a um suposto desenvolvimento 
progressivo do aluno. Um desenvolvimento cujas etapas, pedagogicamente racionalizadas, prometeriam a emancipação e a igualdade como ponto de chegada da jornada educativa. No entanto, a pedagogização da aprendizagem afirma, em ato, a incapacidade de o aluno compreender as obras da inteligência humana por si mesmo, em um contato imediato de sua inteligência com aquela que produziu a obra com a qual dialoga. Em contraposição a esse modus operandi da pedagogia, as lições sobre a emancipação intelectual de Jacotot e Rancière nos propõem a igualdade não como objetivo em direção ao qual se caminha, mas como princípio que atua no presente; como axioma que inspira a tecitura de cenas de igualdade, aqui e agora; como uma forma de se viver um tempo de emancipação que ateste a igual capacidade de todos os humanos de romperem com as hierarquias sociais que atribuem a cada um seu lugar próprio na ordem social da desigualdade.

A emancipação intelectual emerge, assim, não como resultado de uma transmissão pedagógica de saberes, mas como fruto da vontade e da disposição de tecer seu próprio caminho em direção à verificação da igualdade de todos em relação a qualquer pessoa. Daí porque a ignorância do mestre não o impede de emancipar-se e de se comprometer com a emancipação de seus alunos. 0 mestre emancipador não transmite seus conhecimentos, mas sua paixão pela igualdade e pela liberdade de buscar por si próprio a compreensão de qualquer obra da inteligência humana. Ele transmite uma forma de relação com o conhecimento e com os outros; uma perspectiva de mundo e não sua interpretação.

Esse "giro copernicano" operado por Rancière - a igualdade como pressuposto e ponto de partida - repercutiu fortemente no campo dos estudos em educação. A revista brasileira Educação \& Sociedade (v. 24 n.82, abr. 2003) e o periódico francês Le Télémaque (n.44, 2013/2), por exemplo, dedicaram dossiês temáticos à obra $O$ mestre ignorante. 0 mesmo destino teve o artigo Escola, produção, igualdade ([1988] 2018), no qual Rancière afirma que a forma-escola oferece a todos - independentemente de sua origem - um tempo livre das obrigações do mundo do trabalho, um tempo dedicado ao aprender por aprender. Nesse sentido, a escola poderia ser considerada como o espaço da igualdade por excelência, potencialmente capaz de promover a igualdade por sua própria forma, mais do que pela transmissão de conteúdos. Tais reflexões sobre os vínculos entre escola e igualdade têm suscitado intensa produção de autores do campo da filosofia da educação, como Jan Masschelein e Maarten Simons, que propõem a partir delas uma defesa da escola ou Jorge Larrosa, que dela faz um elogio.

Ao longo de toda sua vida intelectual, Rancière publicou inúmeros artigos sobre temas da atualidade e concedeu diversas entrevistas, de modo coerente com seu método da igualdade ([2012] 2014), que não considera as entrevistas como formas menos legítimas ou significativas do trabalho do pensamento - um trabalho que não tem um lugar próprio e está em todas as partes. A entrevista aqui apresentada foi concedida (de modo online) como parte do Colóquio Internacional Educação, política e emancipação no pensamento de Jacques Rancière, realizado em março de 2021 e organizado pelo Grupo de Estudos e Pesquisa em Educação e Pensamento Contemporâneo (GEEPC), vinculado ao Programa de Pós-Graduação da Faculdade de Educação da Universidade de São Paulo (FEUSP). Ela testemunha, precisamente, o trabalho de pensamento de um filósofo em ato, discutindo sua própria trajetória, analisando sua contribuição para a filosofia da educação e refletindo sobre questões do presente. 


\section{A entrevista}

Gostariamos de começar com uma pergunta que não é estritamente acadêmica, é de ordem mais pessoal, sobre a sua relação com o Brasil, com a vida universitária brasileira. Você tem mais de quinze livros traduzidos no país, que são muito estudados em cursos de filosofia, artes e educação. Concedeu várias entrevistas a colegas brasileiros e há alguns anos escreveu um belíssimo artigo sobre Guimarães Rosa e o livro Primeiras estórias. Gostariamos que comentasse como vê sua relação com a cultura brasileira e, mais precisamente, com a vida universitária do país.

Certamente, a relação que tenho com o Brasil é uma relação privilegiada. 0 Brasil foi o primeiro país ao qual fui convidado por uma universidade a falar. Foi há muito tempo, em 1967, quando eu era um jovem althusseriano e fui convidado como tal ao Departamento de Filosofia da Universidade de São Paulo. Um departamento que era povoado por professores jovens, mas muito notáveis, todos prestigiosos e muito calorosos comigo. Foi um início bastante intenso, eu diria, da minha colaboração com o mundo universitário e intelectual brasileiro, onde criei laços de amizade que duraram quase toda a minha vida, pois, infelizmente, algumas dessas pessoas fascinantes já faleceram. Esse foi o ponto de partida e depois disso, em várias épocas, com diversas gerações, universidades e instituições, esse laço foi restabelecido, de modo que ao longo de praticamente meio século tive verdadeiras trocas intelectuais com o Brasil. É simbólico que tenha sido o primeiro país em que fui traduzido, onde o livro $A$ noite dos proletários foi publicado antes de ser traduzido ao inglês, por exemplo. É também o país onde, em dado momento, aconteceu algo que jamais tinha acontecido na França: um grande jornal [A Folha de S. Paulo] me convidou a escrever colaborações regulares, o que permitiu que eu me debruçasse sobre a atualidade política, artística e intelectual brasileira e, certamente, isso nutriu toda minha reflexão política e estética. Além disso, o Brasil é um país que me marcou por sua cultura e esse texto que vocês mencionaram, sobre Guimarães Rosa, que é o último capítulo do meu livro As margens da ficção ([2017] 2019), é para mim uma espécie de homenagem à cultura brasileira. Homenagem prestada a um escritor que é absolutamente fundamental, que é um dos grandes escritores do século XX, mas que, infelizmente, é quase ignorado no meu país. Trata-se, assim, de uma homenagem a esse grande escritor, que representa uma grande literatura.

A segunda pergunta é sobre a sua trajetória intelectual, onde nos parece haver uma passagem da crítica ao intelectual concebido como porta voz da sociedade e dos trabalhadores, em direção a um momento no qual você coloca em cena a palavra daqueles que, até então, ocupavam o lugar de objeto nos discursos intelectuais e acadêmicos. Essa passagem coloca em evidência, a nosso ver, modos bastante diferentes de conceber a relação entre o saber e a política. A questão é: de que maneira, ou em que medida, essa questão foi central nos seus trabalhos dos anos 70 e 80 ? Esse estilo 
de trabalho estaria ligado à palavra de ordem "liberar a palavra", ${ }^{6}$ do movimento de maio de 68 ?

Começarei por uma pequena nuance que me parece importante. Para mim, a palavra de ordem que mais se ouvia em 68 não era exatamente "liberar a palavra", mas "tomar a palavra”. Parece um detalhe, mas liberar a palavra é uma expressão ambígua, porque ela frequentemente quer dizer liberar a palavra que é a mais conforme com o mundo ao seu redor. Hoje em dia, por exemplo, a palavra liberada é a das redes sociais, uma palavra que, afinal de contas, é desigual, cheia de ódio, uma palavra habitada pela ideologia conspiratória. Para mim, o importante em maio de 68 era tomar a palavra. Tratava-se de um apelo lançado a todos aqueles cujas palavras não eram ouvidas ou apenas eram ouvidas como ruídos. Era um apelo a abrir uma cena na qual as palavras eram ampliadas e partilhadas, pois o importante na época era o movimento anti-hierárquico que queria fazer com que fossem ouvidas palavras que não eram ouvidas normalmente, destituindo assim o monopólio da palavra oficial, seja ela estatal ou acadêmica. É verdade que essa palavra de ordem foi importante na minha trajetória e é verdade também que ela passou por dois momentos diferentes.

No primeiro momento, relativo a 68 ou pós-68, isso me levou a fazer um apelo a uma palavra que era sufocada por uma dupla confiscação: aquela operada, por um lado, pela ciência marxista, mas também, por outro, a confiscação operada pelo aparelho político e sindical do partido comunista. Nesse primeiro momento, portanto, havia uma vontade de voltar a um tipo de palavra "de baixo", que havia sido sufocada por uma pressão vinda "de cima”. Isso era fruto da época, do grande tema da revolta antiautoritária, mas ao mesmo tempo isso permanecia, de alguma forma, preso a uma visão dualista, ou seja, preso à ideia de que havia uma palavra de cima e uma palavra de baixo, uma palavra que de alguma forma era "mentirosa" e outra verdadeiramente "autêntica". Isso remetia à ideia de que havia algo como "verdadeiros sujeitos populares" ou "verdadeiros sujeitos operários" e que havia uma palavra autêntica que precisava ser recuperada e que precisava se fazer ouvir contra a palavra dos acadêmicos e a palavra autoritária. Assim, no fundo era algo que ficava preso a essa espécie de dualismo entre uma palavra de cima e uma palavra de baixo; uma palavra dos acadêmicos e uma verdadeira palavra popular, imanente ao corpo popular ou ao sujeito operário. Era algo de que eu precisei me separar em um segundo momento.

Nesse segundo momento, tive que colocar em questão a ideia de uma voz de baixo, da busca pela identificação de uma voz popular autêntica. Afınal, o que me permitiu operar essa separação? Foi certamente o trabalho de pesquisa que culminou em $A$ noite dos proletários e foi também o trabalho de escrita desse livro - e dos meus livros em geral. 0 que aconteceu? De início, ao mergulhar nos arquivos operários, eu me deparei com uma realidade que não tinha nada a ver com uma de voz de baixo que se liberava. 0 que eu vi foi, ao contrário, que a circulação de palavras, os cruzamentos de palavras, todas as

6- No original francês: parole, vocábulo que pode ser traduzido em português por "palavra", "fala" ou "discurso". Optamos aqui por "palavra", mas é importante considerar que se trata de um ato de fala, de algo que alguém enuncia. Seu uso em Rancière remete a uma acepção que se aproxima ao logos em Aristóteles, que também significa "razão", "linguagem". 
formas de apropriação da palavra do outro, da cultura do outro, estavam no cerne dos processos de emancipação. Assim, o que percebi na época foi que não existe a palavra dos intelectuais e a palavra do povo. Somos todas e todos intelectuais. Esses trabalhadores também usam suas cabeças, portanto são intelectuais. 0 que tentei fazer a partir disso foi colocar em evidência essa intelectualidade partilhada por todos. 0 que isso quer dizer? Que devemos desfazer o fechamento das disciplinas e das formas de discurso; que devemos fazer cruzamentos entre palavras e pensamentos que normalmente não se encontram. Por exemplo, retomando coisas que afırmei em várias ocasiões: Platão diz que o trabalhador deve ficar na ofıcina, pois o trabalho não espera, ou seja, o tempo define a restrição que pesa sobre a própria identidade do trabalhador. Ora, fiz essas palavras do grande filósofo antigo encontrarem as palavras de trabalhadores que, no século XIX, também definiam sua condição pelo roubo do tempo, pelo fato de que não tinham tempo. De forma análoga, em meu livro $O$ desentendimento cruzo de modo pouco habitual a tese de Habermas sobre a racionalidade comunicativa com a argumentação de uma greve operária dos anos 1830 . Enfım, foi isso que minha pesquisa me ensinou.

Além disso, há o que aprendi no processo de escrita de A noite dos proletários, que me obrigou a realizar uma ruptura com uma hierarquia normalmente admitida e considerada necessária nas ciências sociais. Em geral, nas ciências sociais há a palavra que é recolhida - a palavra popular, a palavra do trabalhador, a palavra marginal etc. -, que é considerada um material, uma espécie de material bruto; e há a palavra do mestre, do cientista que explica o que significa esse material, em explicações endereçadas à própria comunidade acadêmica. Por imposição do material que encontrei nos arquivos e pela obrigação de falar sobre ele de modo coerente (mais do que por uma espécie de vontade programada), fui levado a operar um duplo deslocamento. Por um lado, finalmente fazer com que essas palavras de operários saíssem do lugar que normalmente lhes era atribuído; por outro, deslocar a minha própria palavra do lugar que lhe era normalmente atribuído: seja da argumentação filosófica, seja da explicação histórica. Fui levado a operar esse duplo deslocamento, a constituir um plano no qual a palavra do acadêmico e a palavra de seu "objeto" não se distinguiam mais. Isso foi importante para mim e a partir daí fui levado a pensar que o trabalho de escrita não é, como se diz habitualmente, a expressão de um pensamento, mas sim o próprio trabalho de pensamento. Fui levado a ver o pensamento como uma certa política. No fundo, o que tentei fazer por meio da escrita foi romper as barreiras entre as disciplinas e entre palavras de cima e de baixo, para constituir o que hoje gosto de chamar de planos de igualdade, esses pequenos tecidos de um mundo da palavra igualitária. Mas é claro que isso é algo que eu não programei desde o início, foi algo que se constituiu ao longo do trabalho, que fui levado a sistematizar a partir da minha leitura dos textos de Jacotot. Fui levado a compreender sua grande ideia de que a igualdade não é algo em que se acredita, a igualdade é um processo que se verifica. Enfim, fui levado a pensar o trabalho acadêmico de uma maneira diferente, buscando praticá-lo justamente como a tecitura de um mundo igualitário. A ideia, portanto, é que igualdade e desigualdade são coisas que se tecem cotidianamente através da maneira mesma como articulamos palavras, argumentos, imagens e narrativas - assim como os seres humanos também podem se juntar de maneiras iguais ou desiguais. É assim que eu poderia descrever 
minha evolução. É claro que digo isso de um ponto de vista retrospectivo, pois na pesquisa segue-se em frente, não se sabe exatamente o que se procura e, depois, passados vinte, trinta anos pode-se dizer: eis o que significou esta pesquisa.

Talvez pudéssemos dizer que seu trabalho, como o de Jacotot, é caracterizado por um tatear, é um "método antimétodo". Por falar em Jacotot, passemos ao seu livro $O$ mestre ignorante, que foi calorosamente recebido no Brasil e até hoje é uma de suas obras mais citadas, ao menos em pedagogia. Ele foi frequentemente considerado um livro sobre um método de ensino, apesar de suas declarações em sentido contrário, apesar do fato de que o insucesso da institucionalização da aventura de Jacotot foi bem descrito no final da narrativa, apesar também da indicação muito clara de que a verificação da igualdade supõe exatamente a ruptura com métodos estabelecidos, ao exigir o ato livre da criação. Essa interpretação paradoxal certamente deve muito ao ethos pedagógico, sempre pronto a disciplinar e determinar regras. Mas será que ela também corresponde, de modo mais geral, na política, ao desejo de encontrar respostas e modelos de ação, como nos parece que às vezes se pede a você? Essa insistência não revela uma concepção muito estreita da relação entre a teoria e a prática?

Sim, penso que o que aconteceu com $O$ mestre ignorante é o que aconteceu com muitos dos meus livros. Diria que, em geral, meu trabalho foi recebido sobre a base de duas pressuposições que evidentemente contradizem a própria lógica desse trabalho. A primeira pressuposição é a de pertencimento a uma disciplina definida. Você fala da história de um professor, portanto é um livro de pedagogia; você fala de trabalhadores, então é história social; você fala de democracia, logo é ciência política - e assim por diante. Evidentemente, essa espécie de partilha de disciplinas está em harmonia com toda a lógica da desigualdade, em que cada um deve estar em seu lugar, em que cada um é competente em sua área e se torna incompetente na área do outro. Essa é a primeira pressuposição que sempre encontrei e em certo sentido contornei. Mas nem sempre. E quando ela não é contornada, ela nos bloqueia.

A segunda pressuposição, efetivamente, é a que vocês mencionaram. No fundo, é uma certa ideia do trabalho do pensamento e de seu efeito sobre as categorias de teoria e prática. Normalmente, pensa-se que uma teoria é algo que deve ser aplicado na prática, mas é evidente que a aventura Jacotot é completamente resistente a esse modelo. 0 "método Jacotot" não é um método de ensino pertencente à ciência pedagógica; pelo contrário, é uma crítica da visão pedagógica do mundo e, consequentemente, de todos os métodos que entram no campo dessa visão pedagógica. Aprofundando um pouco mais, eu diria que o escândalo operado por Jacotot é o bloqueio da própria ideia de aplicação, da ideia de que há um discurso, uma ciência, uma teoria que serão aplicados. À medida que Jacotot fala menos do ensino do que da igualdade, de uma palavra que seja igual, na qual o locutor esteja em um plano de igualdade com seu interlocutor ou interlocutora, essa ideia de igualdade se torna contraditória com a lógica normal das instituições educativas e do ato educativo que nela se opera. É algo que Jacotot formaliza, "explica": a incompatibilidade de um método igualitário, de um desdobramento da palavra 
igualitária com uma instituição que pertence a uma lógica social que é fundamentalmente de reprodução da desigualdade. Qual é a consequência? Penso que tive a oportunidade de falar sobre isso uma vez no Rio de Janeiro, onde tentei explicar que o método de Jacotot obriga todos aqueles que trabalham em instituições educativas, no mundo da educação, a algo como uma divisão de razões. Para seguir os passos da igualdade, para buscar um modo de transmissão ou de circulação igualitária da palavra e do pensamento é necessário, de certa forma, separar essa lógica igualitária da lógica das instituições nas quais isso ocorre. Consequentemente, essa é uma "teoria" que coloca um problema radical, pois o que ela nos obriga a fazer não é uma aplicação, mas de certo modo ela exige uma espécie de inaplicação. Uma divisão de razões que remete a uma divisão mais fundamental: trabalha-se pela igualdade, busca-se fabricar a igualdade, mas no seio de um mundo desigual e de máquinas desiguais que fazem esse mundo funcionar. Bom, na medida em que a palavra de Jacotot é endereçada a pessoas que querem mudar o mundo e também mudar a escola, e que pensam que para mudar o mundo é preciso mudar a escola, e que para mudar a escola é preciso mudar o mundo, suas ideias foram como um "paralelepípedo lançado no lago" dos debates educacionais ${ }^{7}$. $\mathrm{Na}$ época em que publiquei $O$ mestre ignorante, a opinião de Jacotot contrariou ao mesmo tempo os dois grandes adversários no embate sobre a escola: por um lado, aqueles que denominei sociólogos, que afirmavam ser preciso mudar a escola, a forma da escola, para torná-la mais adaptada às populações desfavorecidas; por outro, os ditos republicanos, que afirmavam que, ao contrário, era preciso manter a forma da escola, reforçar seu fechamento, pois ela seria o lugar onde se transmite o saber - e o saber universal tornaria todos iguais. Em relação a isso, Jacotot era duplamente incômodo.

Essa dupla resistência de Jacotot remete mais profundamente a uma certa visão simplista da relação entre teoria e prática. Pensa-se na relação teoria-prática sempre na perspectiva da velha oposição dualista entre pensamento e matéria ou pensamento e extensão. Nessa perspectiva, a teoria é o pensamento e o pensamento é imaterial, enquanto a ação é uma coisa material que será concretizada. Sempre há, portanto, uma demanda de que o pensamento, imaterial, produza efeitos no mundo material. Em geral, a lógica empregada para resolver isso é dizer que o pensamento fornece ferramentas que por sua vez permitem mudar o mundo. Então, o pensamento permite mudar a realidade, como uma picareta, ou permite mirar a desigualdade, como um fuzil, de modo que o pensamento se torna ferramenta ou arma. Penso que essa é uma visão de mundo bastante compartilhada, mas que desconhece completamente o que é o trabalho do pensamento, o trabalho intelectual. 0 pensamento não é uma coisa imaterial, mas uma coisa material, que se exprime em textos, em palavras, em discursos, em livros. 0 que são os livros que escrevi? (Apenas para dar um exemplo, pois é a mesma coisa para todo mundo.) Meus livros são como uma composição de palavras, argumentos, relatos, imagens que constituem algo como um bloco sensivel, um bloco sensivel que traz consigo afeto. No fundo, trata-se de uma condensação de experiências que forma uma proposição de

7 - A expressão francesa utilizada por Rancière foi: "le pavé Jacotot dans la mare éducative". A imagem do "paralelepípedo Jacotot lançado no lago dos debates educacionais" remete ao forte impacto que suas ideias produziram nas águas "tranquilas" do debate pedagógico. 
mundo. Isso retoma o que mencionei anteriormente, de buscar tecer a igualdade. Um livro, para mim, é algo como uma proposição de mundo e, é claro, essas proposições encontrarão auditores, auditoras, pessoas que serão afetadas por esses blocos sensiveis. Nesse momento, as palavras, as imagens, os pensamentos que foram reunidos no livro são de certa maneira desmontados e entram em novas combinações e, consequentemente, fornecem a possibilidade de novas sínteses sensíveis. Sínteses sensíveis que ocorrerão de várias formas: pode ser um livro dito teórico, pode ser um romance, uma obra de arte, uma ação dita política. Em todos os casos, não saímos do domínio do pensamento e entramos no domínio da matéria; passamos de um tipo de síntese sensível a outro tipo de síntese sensível. Isso é feito de um modo no qual o pensamento não é um instrumento ou uma arma para mudar a matéria ou matar o mundo.

Voltando a $O$ mestre ignorante, realmente não se trata de um método de ensino, tampouco da fundação de uma política educacional. É um livro que talvez possa mudar a maneira como somos afetados pelas palavras: a palavra educação, a palavra transmissão, a palavra igualdade, a palavra saber - e talvez seja por isso que ele tenha tido efeito, afinal de contas. 0 livro muda, talvez, a maneira como essas palavras nos afetam. Consequentemente, muda a maneira como esses afetos produzirão comportamentos: maneiras não apenas de ensinar, mas de pensar, de viver, de se emocionar. Tive a oportunidade de refletir sobre isso, pois os primeiros leitores de 0 mestre ignorante, ou melhor, o primeiro meio em que o livro foi influente não foi o meio da educação, mas o da dança. Foi no mundo da dança que as pessoas pensaram que ele tinha a ver com sua arte, a arte do movimento, com a maneira como ela é praticada e ensinada. É algo que tive a oportunidade de repensar recentemente, pois escrevi uma obra chamada Tempos modernos ([2018] 2021), na qual há um capítulo em que explico um pouco como a dança e, em geral, as artes do movimento estiveram no cerne de uma revolução estética que rompeu a velha separação entre o que se chamava de homens livres e homens mecânicos, ou homens ativos e homens passivos. Escrevi $O$ mestre ignorante há cerca de 35 anos e comecei a entrar no âmbito da dança nesse momento; mais recentemente, trabalhei com seu papel na revolução estética, de igualdade estética. Para mim, eram como peças de um quebra-cabeças igualitário que finalmente estava sendo montado. Bom, isso é o que posso dizer sobre a recepção de 0 mestre ignorante, os efeitos que ele não pode produzir e os que ele pode, sim, produzir.

Seu último livro, Les mots et les torts (2021), trata dessa questão, entre outras coisas, não é mesmo?

Sim. Não fui eu quem escolheu esse título [risos], mas é verdade que busquei desenvolver nesse livro o que comentei há pouco, além de precisar ideias que circularam e circulam no meu trabalho, a saber, que as palavras não são realidades abstratas que estão nos textos, são potências concretas, são coisas materiais. E são materiais não apenas quando elas penetram nas grandes massas, como afırmava Marx; são materiais desde o ponto de partida. Isso quer dizer que os conflitos sociais, os danos, a formulação dos danos e seu tratamento sempre passam por polêmicas sobre as palavras, pelas maneiras de argumentar, maneiras de descrever e redescrever, de recolocar em cena a palavra do outro. Sim, isso está no cerne do meu trabalho. 
Passemos ao tema da relação entre escola e igualdade. Sabemos que a reflexão sobre o tempo livre ${ }^{8}$ aparece em diversos momentos da sua obra e que em alguns deles é associada à skholé grega, que você situa como a origem da escola. Ao oferecer tempo livre a todos - inclusive aos filhos da classe trabalhadora - a escola poderia ser vista como "o espaço da igualdade por excelência" e, consequentemente, teria um potencial emancipatório. Entretanto, sabemos que você insiste no fato de que a lógica da emancipação não seria passível de ser institucionalizada, como disse há pouco. Seria isso um paradoxo? Você poderia comentar esse paradoxo?

De início, darei uma resposta bruta, que explicarei em seguida. Para mim não há, de forma alguma, um paradoxo no que eu disse; mas, em contrapartida, a escola é efetivamente uma instituição contraditória em si mesma. Voltemos, então, à minha relação com a escola, com Jacotot e com os vínculos entre escola e igualdade.

É verdade que a questão do tempo livre é central no meu trabalho. Por quê? Pois ela é central naquilo que chamo de partilha do sensível. A partilha do sensível é, primordialmente, uma certa distribuição do tempo, uma certa hierarquia na temporalidade. De acordo com a distinção muito antiga entre homens livres e homens mecânicos, os homens livres são aqueles que dispõem de tempo, dispõem do tempo livre que não é o fato de descansar, de se divertir, mas o fato de ter um tempo que não é finalizado, de gozar de um tempo que é um fim em si mesmo. Em oposição a isso, os homens ditos passivos ou mecânicos são pessoas que vivem no mundo do trabalho e da reprodução, um mundo em que todos os momentos são finalizados por uma necessidade, uma utilidade: é preciso trabalhar, produzir, ganhar a vida e assim por diante. De fato, essa questão da partilha do tempo é fundamental para mim e recordo frequentemente a maneira como ela foi sistematizada, em poucas palavras, por Aristóteles, no livro 8 de A politica, onde ele opõe o tempo livre - o tempo que é uma finalidade em si mesmo - ao repouso. Os homens livres gozam de tempo livre, enquanto os homens mecânicos só podem gozar de uma única forma de interrupção da atividade: o repouso entre dois gastos de energia. Nesse sentido, a questão da conquista do tempo livre e, portanto, da abolição da hierarquia do tempo é central para a noção de emancipação. Essa conquista do tempo livre passou por uma série de aprendizados selvagens, pelos quais homens e mulheres do povo mostravam seu direito a ganhar esse tempo e a gozar de todas as formas de experiência supostamente reservadas às pessoas que têm tempo livre.

Em um livro recente da historiadora Arlette Farge, há linhas belíssimas sobre a mulher de um artesão parisiense do século XVIII que vai à janela para que a vejam lendo, para mostrar que pertence efetivamente ao mundo do tempo livre. Da minha parte, todo o livro A noite dos proletários é sobre essa conquista do tempo livre. Mostrei os modos como ela passava por práticas autodidatas, passava fundamentalmente pelo gesto de subversão do tempo em si mesmo, uma subversão pela qual pessoas decidiram dispor desse tempo que não tinham. Os trabalhadores tomavam o tempo da noite - que normalmente seria

8- A palavra francesa loisir, empregada no original, também poderia ser traduzida por "lazer" ou "ócio", mas optamos aqui por "tempo livre" para enfatizar a importância da dimensão temporal na partilha do sensível. A referência não é a um tempo de descanso, mas a um "tempo livre" no sentido de que não tem uma finalidade extrínseca, é um fim em si mesmo (como Rancière explica na sequência da entrevista). 
usado para o repouso entre duas jornadas de trabalho, para estarem preparados para o trabalho do dia seguinte - e o transformavam em tempo livre, ocupando-o com leitura, escrita e discussão. Penso que foi por meio dessas práticas autodidatas, dessa subversão da ordem do tempo que passou a conquista do tempo livre pelos homens e mulheres do povo, mais do que pela escola em si mesma, enquanto instituição. Isso não quer dizer que a escola como instituição não tenha tido seu papel, à medida que, efetivamente, a escola pública instituiu uma espécie de tempo da separação. Um tempo a princípio destinado ao saber e que foi separado do tempo normal da vida social e, portanto, do tempo normal da reprodução das desigualdades sociais.

Desenvolvi um pouco esse tema especialmente em um artigo antigo chamado Escola, produção, igualdade. Acredito que alguns de vocês o leram e se interrogam sobre ele. É um texto que está de acordo com o que eu disse, principalmente com os princípios da minha análise. Ali, eu mostrava que na França do século XIX opunham-se duas maneiras de formar as crianças para a vida: o modelo da aprendizagem das oficinas e a escola. Naquele contexto, os industriais, por um lado, e os ideólogos (da ideologia dominante), por outro, denunciavam a escola, afirmando ser necessário às crianças do povo se tornarem aprendizes, para não serem retiradas de sua condição e para aprenderem as coisas úteis para seu trabalho; as disposições e virtudes úteis para a vida que teriam depois. A escola, ao contrário, retiraria as crianças de sua condição, faria com que vivessem em um mundo que não era mais o de seus pais, que não era mais aquele que encontrariam depois da escola. Nesse sentido, a escola as faria viver em um mundo de igualdade que seria um mundo de ilusões perigosas. Sabemos, contudo, que esse é um discurso bastante enviesado, pois, na realidade, ser aprendiz em uma oficina ou fábrica não era algo formador no sentido da aprendizagem de coisas úteis ou práticas. Era muito mais formativo no sentido da aprendizagem das condições em que se deve obedecer e reconhecer sua inferioridade. Consequentemente, a oposição entre o saber útil e o saber não útil de fato escondia outra coisa: a oposição entre um modo de preparação para uma vida de servidão ou um modo de preparação para uma vida de igualdade. Em relação a isso, a escola teve certo papel, justamente enquanto instituição do tempo livre, mais do que pelo saber que ela distribui.

Era essa a questão do texto, algo que foi importante, que nutriu em certo momento a polêmica, mas, ao mesmo tempo, não devemos esquecer que a escola pública integrou, muito rapidamente, a separação dos tipos de formação. A escola pública, ao menos no meu país, rapidamente distinguiu ciclos curtos - oferecidos às pessoas destinadas ao mundo do trabalho, com os saberes e virtudes ditos úteis - e um ciclo longo, destinado a preparar as pessoas da elite, com a cultura clássica, um saber científico, não utilitário. Houve, assim, no próprio seio da instituição escolar, uma espécie de reprodução da divisão entre a escola e o modelo do aprendiz. Nos nossos tempos, é verdade que, ao menos no meu país, essa distinção está desaparecendo. Instituíram-se ciclos comuns de instrução geral para todo mundo e elevou-se a idade do ensino obrigatório a 18 anos. Infelizmente, o efeito que isso teve não foi de beneficiar a todos com a famosa cultura geral; o efeito, ao contrário, foi de invalidar, desvalorizar um pouco a dita cultura geral. E o principal efeito, infelizmente, foi o de estabelecer uma nova hierarquia, a saber, uma hierarquia entre as escolas: as escolas dos bairros abastados e as escolas dos bairros em dificuldade, as escolas dos ricos e as 
escolas dos filhos dos imigrantes. A escola, assim, teve sua vocação igualitária contrariada pela realidade da desigualdade social, de modo bastante rápido.

Ademais, acredito que há algo no próprio conceito da instituição escolar, em seu funcionamento, para além das questões de origem e destino social. Eu diria que a instituição escolar não é uma instituição da skholé, pois a skholé é um tempo que é livre, um tempo não finalizado. Ora, a instituição escolar é uma instituição ultrafinalizada, a instituição finalizada por excelência, em que cada etapa deve preparar uma etapa seguinte, cada ensino deve preparar uma avaliação e cada avaliação será também uma maneira de definir os que sabem mais, os que sabem menos, os que são mais inteligentes, os que são menos e assim por diante. Portanto, é preciso ver que a instituição escolar não é, desse ponto de vista, uma instituição da skholé. Ao contrário, é uma instituição que fornece quase uma identidade entre o progresso do saber e uma marcha normal do tempo. No fundo, o que acontece é que cada vez mais a escola se torna uma espécie de modelo da sociedade, ou a sociedade, um modelo de escola. Ou seja, há uma homologia crescente entre o tempo da escola e o tempo da sociedade. A escola se tornou uma espécie de modelo para esse mundo social em que vivemos, onde nos dizem que não há divisão, não há hierarquia; que há apenas a marcha do tempo, das coisas, o progresso, o desenvolvimento - e há aqueles que acompanham e aqueles que não acompanham, como na escola, onde há aqueles que têm sucesso e aqueles que não têm. Enfim, acredito que todas essas dimensões devem ser levadas em conta na discussão das relações entre escola e igualdade.

De fato, essa discussão é muito importante, pois muitos de nós continuamos a pensar na possibilidade de fazer skholé, de experimentar a suspensão do tempo e a igualdade na escola. Mas passemos à nossa última pergunta, sobre o mundo contemporâneo. Recentemente, você escreveu sobre a invasão ao Capitólio [ocorrida em 6 de janeiro de 2021] e sobre o apoio popular a Donald Trump. Esse tema nos interessa muito, por analogia com o que temos vivido no Brasil. Nesse artigo (2021), você menciona que o que vemos todos os dias é "a volta do ódio a todas as formas de igualdade". Em $O$ espírito das leis, Montesquieu afırma que a virtude republicana por excelência - o amor à igualdade - deve ser cultivada pela educação. Você acredita que as escolas fracassaram nessa tarefa republicana? Ou essa incapacidade de cultivar o amor pela igualdade, essa paixão pela desigualdade seria um fracasso político e social, mais do que educativo?

Eu conheço pouco do funcionamento da escola norte-americana, ainda que tenha netos que frequentam a escola naquele país. Não sei muito bem o lugar que a educação para a igualdade tem hoje nos EUA, mas acho que lá, como na França, na Europa e, temo, no Brasil e na Argentina (me corrijam se digo besteiras), acho que em todos esses países o fato dominante atualmente é uma hierarquização crescente de escolas, uma distinção cada vez mais forte entre as boas e as más instituições. Aquelas onde se paga mais caro são mais bem vistas do que as outras e mesmo entre as escolas públicas e gratuitas, as boas instituições são aquelas de bairros abastados, onde os ricos vivem entre si e as escolas ruins são reservadas às populações migrantes, pobres e assim por diante. Há essa espécie de 
hierarquia que começa com a educação infantil e faz com que, em muitos países, procurese escolher o futuro do seu filho matriculando-o em uma determinada escola de educação infantil e não em outra. Isso começa no maternal e vai até os rankings acadêmicos; é a realidade do mundo escolar e universitário, a realidade de sua inserção no mundo social hoje, uma adaptação cada vez mais forte a um mundo que é o da desigualdade.

Para dizer que a escola fracassou em sua vocação igualitária seria preciso pensar que ela sempre teve como vocação criar igualdade. Infelizmente, penso que essa vocação igualitária da escola faz parte das ideias do passado, das formas sociais do passado, das concepções progressistas, das instituições progressistas que foram, em certa medida, todas varridas pelo capitalismo selvagem e absolutizado - que batizamos, não sei por que, com o nome elogioso demais de neoliberalismo. Eu diria que a vocação igualitária da escola foi verdadeiramente contestada junto com todas as formas sociais que criavam igualdade ou que lutavam contra a desigualdade. Foi contestada ao mesmo tempo em que o foram as redistribuições fiscais (que tomavam impostos dos ricos para permitir que os pobres vivessem melhor), o serviço público, as formas de seguridade social e todas as leis de proteção social. Tudo isso, pouco a pouco, encontra-se reduzido ou suprimido com a absolutização do capitalismo, assim como as forças igualitárias, coletivas, tradicionais encontram-se hoje enfraquecidas. Penso que o papel dominante da escola hoje é, em certo sentido, manter a criança na trajetória a que seu nascimento a destina, muito mais do que promover grandes redistribuições igualitárias.

Sob o nome de neoliberalismo, há uma espécie de contrarrevolução que é extremamente violenta. Essa contrarrevolução organiza um mundo à sua imagem; um mundo que não é apenas um mundo de exploração, de dominação, de desigualdade reforçada, mas um mundo de percepção, um mundo de afetos ligados à sua imagem. $\mathrm{Ou}$ seja, um mundo onde a desigualdade não é apenas aceita, mas se torna amada; tornase uma virtude, uma virtude partilhada, um objeto de amor. Parece-me que isso está na lógica do capitalismo absolutizado da qual nossos Estados participam inteiramente. Poderia se dizer que nem sempre é o caso, que há diferenças, que o governo no Brasil não é o mesmo que há dez anos. Falo, é claro, de uma tendência geral e, mais especificamente, falo de Trump, do que ocorre nos Estados Unidos.

Em torno desses reforços das desigualdades, das explorações do capitalismo selvagem, há também uma atividade intelectual que é bastante significativa, especialmente no meu país. Aqueles que são considerados intelectuais, que são vistos na televisão e que escrevem nos jornais são pessoas apaixonadas pela desigualdade, pessoas que denunciam toda forma de igualdade como uma monstruosidade ou como islamoesquerdismo. Há um esforço para que mais pessoas participem do gozo da desigualdade, do amor pela desigualdade. 0 que acontece todos os dias nas redes sociais, o que vemos na França quando lemos os comentários que leitores fazem nos jornais online é uma espécie de paixão pela desigualdade, de ódio da igualdade, que se propaga, que circula todos os dias, que se renova, que se tornou uma paixão louca. Penso que talvez seja preciso ver isso em relação ao que se passou com Trump.

No texto que vocês mencionaram, tentei me opor a algumas análises pseudossociológicas da adesão de 75 milhões de habitantes à loucura de Trump. Essas análises dizem que ele é o defensor das pessoas simples contra as elites, que seu sucesso 
vem das pessoas que perderam sua posição social devido à desindustrialização, como se 75 milhões de pessoas fossem desempregadas das fábricas do Michigan, o que é uma piada. 0 que precisa ser visto é que aquilo que essas pessoas chamam de elite, ou que lhes é feito odiar como elite, é na verdade o contrário: são pessoas que eles podem pensar que lhes são inferiores. Fiquei muito surpreso com a semelhança entre o que acontece hoje com a desigualdade e aquilo que descreve Jacotot, que chamei de lógica dos inferiores-superiores, a saber, que a lógica da desigualdade é a lógica na qual todos que são inferiores devem se descobrir como superiores, como superiores a outros, ou devem manter sua superioridade, seu privilégio. Acho que isso é algo que ficou muito perceptível no caso da campanha de Trump e na ampla adesão que ela teve. Foi também o que vimos em vários países europeus, especialmente na França, com o sucesso dos polemistas de direita e extremadireita e com o alinhamento da opinião sobre esses polemistas. 0 povo de Trump não é um povo formado por pessoas ignoradas pelo desenvolvimento econômico; trata-se de um povo em que todos têm uma superioridade a defender. Os trabalhadores mal remunerados creem em sua superioridade sobre os desempregados; os desempregados brancos creem em superioridade sobre os desempregados negros; os desempregados nativos, sobre os desempregados mexicanos; os homens, sobre as mulheres - e assim por diante. Penso que esse mundo da desigualdade apaixonada, da paixão pela desigualdade é o que se manifestou na campanha de Trump e que se manifesta em várias campanhas de sucesso de ideólogos e políticos de extrema-direita ao redor do mundo: da Hungria ao Brasil, na Polônia e na França, entre outros.

Gostariamos de agradecê-lo vivamente, professor, pela generosidade de partilhar conosco seu tempo, suas ideias, suas palavras. É um verdadeiro prazer poder dialogar com você, com seus livros, com seu pensamento. 0 que você propõe é um modo de pensar diferente, que nos convida a abandonar as disciplinas e as hierarquias entre teoria e prática, entre superiores e inferiores. Em tempos tão sombrios como os que vivemos, ele nos inspira profundamente. Esperamos que sua relação com o Brasil, que começou há tantos anos, continue por muito mais tempo. Muito obrigado!

Muito obrigado a todas e a todos.

\section{Referências}

RANCIÈRE, Jacques. A noite dos proletários: arquivos do sonho operário. Tradução de Marilda Pedreira. São Paulo: Companhia das Letras, [1981] 1988.

RANCIÈRE, Jacques. A partilha do sensível: estética e política. Tradução de Mônica Costa Netto. São Paulo: Ed. 34, [2000] 2005.

RANCIĖRE, Jacques. As margens da ficção. Tradução de Fernando Scheibe. São Paulo: Ed. 34, [2017] 2021.

RANCIÈRE, Jacques. El método de la igualdad: conversaciones con Laurent Jeanpierre y Dork Zabunyan. Tradução de Pablo Betesh. Buenos Aires: Nueva Visión, [2012] 2014. 
RANCIÈRE, Jacques. Escola, produção, igualdade. Pro-Posições. Campinas, v. 29, n. 3 (88), p. 669-686, set./dez. [1988] 2018. Tradução de Aimberê Guilherme Rocha do Amaral.

RANCIÈRE, Jacques. La leçon d’Althusser. Paris: La Fabrique, [1974] 2011.

RANCIÈRE, Jacques. Le philosophe et ses pauvres. Paris: GF-Flammarion, [1983] 2007.

RANCIÈRE, Jacques. Les mots et les torts: dialogue avec Javier Bassas. Paris: La Fabrique, 2021.

RANCIÈRE, Jacques. 0 conceito de crítica e a crítica da economia política dos Manuscritos de 1844 a 0 Capital. In: ALTHUSSER, Louis et al. Ler 0 capital. Tradução de Nathanael Caixeiro. Rio de Janeiro: Zahar, [1965] 1979. p. 75-172.

RANCIĖRE, Jacques. 0 desentendimento: política e filosofia. Tradução de Ângela Leite Lopes. São Paulo: Ed. 34, [1995] 1996.

RANCIÈRE, Jacques. 0 espectador emancipado. Tradução de Ivone C. Benedetti. São Paulo: Martins Fontes, [2008] 2012.

RANCIÈRE, Jacques. 0 mestre ignorante: cinco lições sobre a emancipação intelectual. Tradução de Lílian do Valle. Belo Horizonte: Autêntica, [1987] 2015.

RANCIĖRE, Jacques. 0 ódio à democracia. Tradução de Mariana Echalar. São Paulo: Boitempo, [2005] 2014.

RANCIĖRE, Jacques. Tempos modernos: arte, tempo, política. Tradução de Pedro Taam. São Paulo: n-1, [2018] 2021.

RANCIÈRE, Jacques. Tolos e sábios: reflexões sobre o fim da presidência de Trump. Revista Beira. Tradução de Pedro Caetano Eboli. Disponível em: https://medium.com/revista-beira/tolos-e-s\%C3\%A1bios-reflex\%C3\%B5essobre-0- fim-da-presid\%C3\%AAncia-de-trump-8ab1e44411b4. Acesso em: 20 mar. 2021. 